\title{
Os anexos embrionários de aves: revisão de literatura
}

The embryarian annexes of birds: literature review

Los anexos embriarios de las aves: revisión de la literatura

Recebido: 30/01/2021 | Revisado: 05/02/2021 | Aceito: 19/02/2021 | Publicado: 28/02/2021

\author{
Ana Indira Bezerra Barros Gadelha \\ ORCID: https://orcid.org/0000-0001-7541-1646 \\ Universidade Federal Rural do Semi-Árido, Brasil \\ E-mail: anaindirabezerra@hotmail.com \\ Ana Caroline Freitas Caetano de Sousa \\ ORCID: https://orcid.org/0000-0001-5883-9704 \\ Universidade Federal Rural do Semi-Árido, Brasil \\ E-mail: carolfreitas04@outlook.com \\ João Augusto Rodrigues Alves Diniz \\ ORCID: https://orcid.org/0000-0001-5329-9059 \\ Universidade Federal Rural do Semi-Árido, Brasil \\ E-mail: joao-diniz15@hotmail.com \\ Carlos Eduardo Bezerra de Moura \\ ORCID: https://orcid.org/0000-0002-7960-5373 \\ Universidade Federal Rural do Semi-Árido, Brasil \\ E-mail: carlos.moura@ufersa.edu.br \\ Antonio Chaves de Assis Neto \\ ORCID: https://orcid.org/0000-0002-6260-661X \\ Universidade de São Paulo, Brasil \\ E-mail: antonioassis@usp.br \\ Moacir Franco de Oliveira \\ ORCID: https://orcid.org/0000-0002-6269-0823 \\ Universidade Federal Rural do Semi-Árido, Brasil \\ E-mail: moacir@ufersa.edu.br
}

\begin{abstract}
Resumo
Para que os vertebrados vivíparos, incluindo as aves que possuem seu desenvolvimento embrionário dentro do ovo tenham condições de sobreviver no período embrionário, esses necessitam de anexos embrionários (âmnio, cório, alantoide e saco vitelínico). Apesar de ser um assunto relevante, ainda não havia levantamento literário que demonstrasse a disposição, formação, função, utilização em linhas de pesquisa e aspectos específicos desses anexos nas mais diversas aves, tendo isso em vista, o objetivo dessa revisão é fazer esse levantamento. Assim, a mesma apresenta um estudo de pesquisa bibliográfica do tipo qualitativo com características descritivas e forneceu informações que auxiliam na compreensão de vários mecanismos durante a formação do embrião e o progresso do desenvolvimento dentro do ovo, como perspectiva futura espera-se que essa pesquisa sirva de impulso para que novas pesquisas na área sejam desenvolvidas que possam também promover o desenvolvimento científico.
\end{abstract}

Palavras-chave: Aves; Desenvolvimento embrionário; Anexos extraembrionários.

\begin{abstract}
In order for viviparous vertebrates, including birds that have their embryonic development inside the egg, to be able to survive in the embryonic period, they need embryonic attachments (amnion, corium, allantois and yolk sac). Despite being a relevant subject, there was still no literary survey that demonstrated the disposition, training, function, use in lines of research and specific aspects of these annexes in the most diverse birds, having this in mind, the purpose of this review is to make this survey, the review presents a qualitative type study of bibliographic research with descriptive characteristics and provided information that helps to understand various mechanisms during the formation of the embryo and the progress of development within the egg, as a future perspective this research is expected to serve as a boost so that new research in the area is developed that can also promote scientific development.
\end{abstract}

Keywords: Birds; Embryonic development; Extraembryonic attachments.

\section{Resumen}

Para que los vertebrados vivíparos, incluidas las aves que tienen su desarrollo embrionario dentro del huevo, puedan sobrevivir en el período embrionario, necesitan inserciones embrionarias (amnios, corion, alantoides y saco vitelino). A pesar de ser un tema relevante, aún no existía un relevamiento literario que demostrara la disposición, formación, función, uso en líneas de investigación y aspectos específicos de estos anexos en las más diversas aves. La revisión 
presenta un estudio de tipo cualitativo de investigación bibliográfica con descripciones características e información aportada que ayude a comprender diversos mecanismos durante la formación del embrión y el avance del desarrollo dentro del óvulo, como perspectiva futura se espera que esta investigación sirva de impulso para que se desarrollen nuevas investigaciones en el área que también puedan promover el desarrollo científico.

Palabras clave: Aves; Desarrollo embrionario; Inserciones extraembrionarias.

\section{Introdução}

Desde o período Paleozóico a presença das membranas fetais, da relação materno-fetal e das estratégias reprodutivas contribuíram para a diversidade evolutiva e ecológica dos animais amniotas (Ferner \& Mess, 2011). Sendo o ovo amniótico uma estratégia evolutiva e adaptativa dos animais aquáticos ao ambiente terrestre, marcado pela presença de membranas extraembrionárias, âmnio, córion, alantoide e saco vitelínico (Gabrielli et al., 2010; Monteiro, 2017).

Com o auxílio das membranas embrionária (cório, âmnio, alantoide e saco vitelínico) os vertebrados vivíparos adquiriram condições de sobrevivência durante seu período embrionário (Björkman, 1982). Esses anexos embrionários originam-se do mesoderma extraembrionário, ectoderma e endoderma, respectivamente (Mossman, 1987; Vanderley \& Santana, 2015; Monteiro, 2017).

As aves são classificadas como animais amniotas, ovipositores, com todo o desenvolvimento das membranas embrionárias ocorrendo dentro do ovo (Romanoff, 1960). Considerando que os conteúdos dos compartimentos extraembrionários são essenciais para as funções vitais do embrião, como respiração, circulação, digestão e proteção (Hincke et al., 2019).

O embrião das aves já foi usado como modelo experimental, visando a exploração da biologia (Stern et al., 2004), e seus anexos foram utilizados como base para modelos farmacêutico (Vargas et al., 2007), para estudo sobre a de embriologia, morfologia, bioquímica e fisiologia (Narbaitz et al., 1995), para estudos de neoplasias, angiogênese (Ribattii et al., 2012) e embriotoxicidade (Winter et al., 2013).

Apesar de relevante para utilização em diversas pesquisas, ainda não há nenhum levantamento literário que demonstre como os anexos embrionários estão dispostos nos mais diversos tipos de aves. Assim o presente trabalho tem como objetivo realizar o levantamento bibliográfico sobre os anexos embrionários para contribuir com o entendimento biológico, morfológico e científico.

\section{Metodologia}

O presente trabalho apresenta um estudo de pesquisa bibliográfica do tipo qualitativa com características descritivas com base na metodologia de pesquisa (Pereira et al., 2018)

Desta forma, foi realizado uma revisão de literatura com suporte em estudos disponíveis em bases de dados eletrônicos como Scielo, ScienceDirect, PubMed, Periódicos capes e Google acadêmico e devido à grande relevância foram feitas manualmente pesquisa em livros e periódicos impressos.

O critério de inclusão foi a partir da seleção dos periódicos, livros, dissertações e teses mais relevantes, tanto inglês como em português, assim como foram incluídos artigos a partir do ano de 1930, isso devido à grande relevância intelectual para o tema abordado. 


\section{Revisão de literatura}

\subsection{Saco Vitelínico}

A primeira membrana a se formar é a do saco vitelino (Mossman, 1987). Essa membrana inicialmente é avascular, porém posteriormente torna-se o primeiro local de vaculogênese (Burton \& Tullet, 1985).

De acordo com Wooding e Flint (1994) o saco vitelínico inicialmente é formado por uma única camada celular proveniente da ectoderme, podendo ainda ser denominado como, saco vitelínico unilaminar ou onfalopleura, migrações sucessivas da camada interna da endoderme para a ectoderme formam o saco bilaminar, e o crescimento da mesoderme entre as duas camadas dará origem ao saco vitelínico trilaminar.

Em relação às funções do saco vitelínico, vários autores contribuíram para essa compreensão, visto que o saco vitelino possui uma função nutricional (Mossman, 1987), função absortiva, pois absorve a gema para nutrir o embrião (Burton \& Tullet, 1985), e participa junto com a membrana corioalantóide do processo de troca gasosa (Mortola, 2009).

Em codornas Padgett e Ivey (1960) apresentaram algumas características do saco vitelínico no desenvolvimento inicial desses animais. Eles observaram que na maioria dos animais, o saco vitelínico estava quase completo no segundo dia de incubação, a partir do décimo terceiro dia, viram que esse recuou para uma cavidade do corpo e começou a inverter, e que no décimo quarto dia recuou ainda mais, já no décimo quinto se inverteu completamente, e no dia posterior a essa inversão, os animais que foram incubados mais cedo, eclodiram.

Também em codornas Yoshizaki et al. (2002) descreveram o saco vitelínico por meio de imunoeletromicroscopia e observaram que esse consistia em duas camadas de células, uma ectodérmica e outra endodérmica. Nas células ectodérmicas, havia vários grânulos de densidade eletrônica semelhante à do albúmen, com diâmetro de 1 um ou menos, além de pequenas vesículas no interior dos grânulos, tornando-os corpos multivesiculares.

Em galinhas, Bakst e Howard (1977) observaram em microscopia eletrônica de transmissão que as projeções do espaço perivitelino (pólo animal) no saco vitelínico era composto por microvilosidades simples e múltiplas, ramificadas e com projeções irregulares. Verificaram também que a membrana do saco vitelino possuiu uma aparência trilaminar. As análises com microscopia eletrônica de varredura permitiram que os autores inferissem que há locais com predominância de microvilosidades. Posteriormente Sugimoto et al. (1999) observaram também em galinhas que as proteínas do albúmen se movem para gema e para o embrião (absorção para nutrição) por meio do saco vitelínico.

Em estudos mais recentes utilizando ovo de galinha, Hincke et al. (2019) descreveram que a membrana vitelínica forma uma matriz proteica extracelular em torno da gema e do oócito e que essa membrana fornece uma separação física do albúmen, também descrevem que essa consiste principalmente de proteínas estruturais fibrosas e polipeptídios antibacterianos. Segundo os pesquisadores, a membrana, possui camada interna e externa. Na camada interna eles observaram proteínas da zona pelúcida, que permitem a adesão de espermatozoides, durante a fertilização. Já a camada externa forma-se após a ovulação, no local da fertilização, essa membrana fornece benefícios físicos e proteção molecular para impedir que patógenos atinjam a gema do ovo.

Se tratando de frangos Fairchild et al. (2006) realizaram um estudo na qual relataram que o saco vitelínico é internalizado na cavidade abdominal com 18 dias de incubação e em seguida é usado como fonte de nutrientes e energia pelo animal chocado, sendo completamente absorvido após 14 dias da eclosão, e que isso, acontece em outras as aves, exceto em aves na qual os filhotes não absorvem todo o saco vitelínico e esse persiste ao longo de toda a vida, como é o exemplo de alguns pássaros.

Também em frangos, Baggott (2009), descreveu o saco vitelínico como sendo a primeira membrana extraembrionária a se desenvolver, composta por três camadas celulares, sendo a área externa do blastoderme. A primeira camada estaria representada pela ectodérmica adjacente as membranas vitelinas, a segunda, como endodérmica adjacente para gema e a outra, 
entre as duas camadas, uma camada de células do mesoderma. $\mathrm{O}$ autor, também discorreu que a camada do mesoderma é dividida em duas por uma cavidade, a primeira divisão diz respeito ao celoma extraembrionário, a segunda o mesoderma próximo a endoderme, onde se desenvolve os vasos sanguíneos (mesoderma vascular). São essas duas camadas celulares, que formam descritas como a parede definitiva do saco vitelino.

Yadgary et al. (2011) inferiram no estudo com embrião de frangos, que o saco vitelínico não é responsável apenas, pelo transporte de nutrientes da gema para o pintinho, mas também é de suma importância, por ser o local de produção de células sanguíneas primitivas e síntese de proteínas específicas.

Posteriormente Réhault-Godberte e Guyot (2018), por sua vez, relataram que o saco vitelínico é incorporado como parte do intestino delgado dos pintos em formação e representa uma estrutura que fornece nutriente e proteção aos pintinhos recém-eclodidos, até que esses possuam seu trato digestivo completo e sistema imunológico funcional.

\section{2 Âmnio}

O âmnio é um saco membranoso, completo pelo líquido amniótico, proveniente de um dobramento da ectoderme e acompanhado pela mesoderme somática (Vanderley \& Santana, 2015) e é o anexo que possui maior relação com o embrião, pois se encontra envolto ao feto, e tem função de proteção contra choque mecânicos e microrganismos (Monteiro, 2017).

Em aves domésticas Baggott (2009) relatou a maneira que o âmnio forma algumas de suas características: Primeiro ele descreveu que o âmnio é formado a partir de uma camada de ectoderma, sendo essa a camada interna, e de uma camada de mesoderma avascular subjacente ao embrião, como sendo, a camada externa. Dentro do mesoderma, ele caracterizou que apareceram as células musculares e essas tornam o âmnio contrátil. Em seguida, descreve como os vasos sanguíneos do âmnio surgiram e cita que isso aconteceu a partir da fusão do mesoderma vascular e avascular do alantoide, posteriormente cita que um ducto se desenvolve, entre o saco do albúmen e o saco amniótico e que se torna responsável pela conexão sero-amniótica e essa conexão, segundo o mesmo, permite o movimento de proteínas do albume para dentro do líquido amniótico e em seguida para o saco vitelínico.

Em frangos, Randles e Romanoff (1954) avaliaram a capacidade tampão de alguns dos líquidos extraembrionários, e descreveram o pH do âmnio nos dias 8,10,12, 14 e 16 de desenvolvimento e como resultado obtiveram que nos dias 8,10,12, a capacidade tampão foi nula e o $\mathrm{pH}$ constante.

Em galinhas, Piechotta et al. (1998) analisaram o impacto dos aminoácidos exógenos nos componentes endógenos dos compartimentos fluídos do embrião, esses relataram indícios de que as barreiras entre o sangue, o âmnio e o alantoide sugeriram que a concentração de aminoácidos e de outras substâncias são regulados no líquido amniótico e alantoide, por meio de mensageiros humorais. Os autores também conseguiram identificar e confirmar 40 aminoácidos e compostos relacionados nos fluidos amnióticos e alantoides ou no plasma sanguíneo.

Em patos, Shbailat e Abuassaf (2018) observaram que após o vigésimo quarto dia de incubação, o líquido amniótico é completamente absorvido pelo embrião. No fluído amniótico, foi observado em eletroforese em gel que bandas de proteínas, incluindo ovalbumina e lisozima, lembram as do albúmen, sugerindo a transferência de proteínas dessas para esse fluido amniótico nessa espécie.

Por sua vez, Dertkigil et al. (2005) ressaltaram a importância do líquido amniótico, demonstrando que esse é fundamental no desenvolvimento dos sistemas musculoesquelético, gastrointestinal e respiratório fetal das aves.

Em relação à histologia do âmnio, Chang et al. (2010) relataram que esse é formado por uma camada epitelial de células cuboides, que faz parte da parede interna da cavidade amniótica, conhecida como ectoderme amniótica, e são provenientes do amnioblasto. O líquido amniótico apresenta três tipos celulares, uma de células epiteliais, outra de células amnióticas e por últimas células fibroblásticas (Gucciardo et al., 2008). 
Durante a incubação de ovo aviário, Hincke et al. (2019) relataram que a membrana amniótica representa a última barreira física antes de atingir o embrião. Inicialmente, essa contém apenas algumas células, depois aparecem células epiteliais em sua superfície, além de uma matriz fibrosa que parece fortalecer a estrutura, pois segundo os mesmos a plasticidade dessa membrana é essencial para apoiar a entrada de água desde o início do desenvolvimento e no albumem durante a segunda metade da incubação.

Hincke et al. (2019) também afirmam que durante a segunda metade da incubação, o fluido amniótico é reabsorvido direta ou indiretamente pelo embrião e que isso ocorre para apoiar a aceleração do metabolismo do mesmo durante a fase de crescimento.

\subsection{Alantoide}

De acordo com Monteiro (2017) o alantoide é uma membrana extraembrionária que é formada da endoderme, especificamente descrito por Vanderley e Santana (2015) como formado a partir do divertículo da parede ventral do intestino posterior, inicialmente possui formato de um saco e posteriormente se espalha entre as paredes do âmnio, e envolve a cavidade amniótica e saco vitelínico.

Suas funções em aves são descritas por vários autores como, depósito de excreção do embrião, devido ao alantoide ser o lugar onde o embrião excreta o ácido úrico, essas excreções renais são conduzidas por via ducto alantoide (proveniente da região da cloaca), função respiratória, pois para executar as trocas gasosas entre o embrião e o meio, esse cresce até chegar à casca do ovo (Vanderley \& Santana, 2015), auxilia na formação óssea a partir do transporte de cálcio até a casca do ovo (Monteiro, 2017), e na hematopoiese (Dieterlen-Lièvre et al., 2010).

Deeming (2002) estudando a incubação de aves descreveu que o líquido alantoide é um resíduo dos rins, que em desenvolvimento aumentam a amônia, ureia e ácido úrico. Sua camada interna é composta por endoderme, e a externa pela camada de mesoderme vascular. A partir do quinto dia, os resíduos renais são destinados ao alantoide, por meio do ducto alantoide. No sexto dia, o mesoderma alantoideano é fusionado com o cório e mesoderme avascular do âmnio, para formar o corioalantóide (Baggott, 2009).

Em relação a sua morfologia, Gabrielli et al. (2010) relataram que o epitélio alantoideano é uma fina camada de célula cuboides, responsável pela reabsorção de água, proveniente do fluido alantóico, atuar como uma barreira seletivamente permeável, permitindo a absorção de eletrólitos, mantendo uma defesa eficaz contra conteúdos tóxicos intraluminais, função esta que está relacionada com as numerosas junções celulares presentes entre as células luminais.

Em codornas, Padgett e Ivey (1960) relataram que no terceiro dia de desenvolvimento o alantoide varia em tamanho, de muito pequeno para uma grande estrutura vesicular, quase tocando a cabeça do embrião.

Em galinhas, Silva et al. (2017) evidenciaram que o saco alantóico é como um divertículo do intestino embrionário, que tem a capacidade de se estender e aumentar a absorção de nutrientes semelhantemente ao saco vitelínico e que esse começa a se fundir com cório em algumas áreas, formando assim, a membrana corioalantóide.

Hincke et al. (2019) observaram que os aminoácidos, peptídeos e proteínas resultantes do metabolismo embrionário são secretadas no saco alantóico, de onde podem ser reabsorvidos pela membrana corioalantóica. Essa membrana cobre todas as estruturas do ovo, sendo vista, como uma segunda barreira física após a casca do ovo durante o desenvolvimento. Também comentaram a respeito da transferência de proteínas intestinais para o saco alantóico, sugerindo que pode acontecer de forma direta.

Na conclusão do mesmo estudo anteriormente mencionado, Hincke et al. (2019) discorrem sobre a evolução do modelo de reprodução ovípara para o modelo vivíparo e sobre distinções importantes entre as estruturas extraembrionárias das aves e dos seres humanos, na qual, em seres humanos, o saco alantoico faz parte do cordão umbilical, por isso a urina é 
secretada no saco amniótico; já nas aves, o saco alantoico é uma estrutura independente, então os resíduos metabólicos são secretados nesse saco.

\subsection{Cório}

O cório é uma membrana extraembrionária que forma a parede externa do blastocisto, formado por duas camadas de trofoblásto e pela mesoderme extraembrionária, unindo-se com o alantoide para desempenhar função respiratória e está localizado logo abaixo da casca. O epitélio coriônico indiferenciado pode ter função de proteção, contra a difusão de íons para dentro do embrião, antes do momento em que o cálcio e o bicarbonato são exigidos para o desenvolvimento do embrião (Gabrielli et al., 2010).

Vanderley e Santana (2015) afirmaram que a membrana do cório possui um grande contato com as membranas da casca e por isso mobilizam minerais da casca para a construção do esqueleto e ajudam também na respiração. Esta membrana em um ovo em processo de incubação interage com o alantoide formando a membrana corioalantóide.

Essa interação acontece por meio da união entre o epitélio do alantoide, cório e mesoderma. O epitélio alantoideano é proveniente do seu próprio endoderma, sendo este separado do mesoderma pela membrana basal (Lusimbo, 2000), já o epitélio coriônico é derivado do ectoderma (Flumerfelt \& Gibson, 1969).

Em frangos, Ribatti et al. (2001) relatam que o processo de fusão entre o cório e o alantoide para criar a membrana corioalantóide é um processo dirigido pelo aumento rápido da vesícula alantóica que ocorre a partir do $4^{\circ}$ até o $10^{\circ}$ dia de incubação nesses animais, promovendo a fusão dessas estruturas.

Também em frangos Banggott (2009) discorreu que o cório desenvolve-se a partir de tecido contínuo com o âmnio e longe do embrião, relatou que o cório é composto por uma camada externa de ectoderma adjacente à membrana interna da casca do ovo e um mesoderma avascular interna, que reveste o celoma extraembrionário. O mesoderma deste se funde com o mesoderma vascular do alantoide, suprindo-o de vasos sanguíneos e formando a membrana corioalantóide, que cobre a área das membranas da casca de ovo, atuando como a superfície respiratória primária do embrião durante a segunda metade da incubação.

Já em codornas Yoshizaki et al. (2002) ao estudarem o cório por imunoeletromicroscopia descreveram esse como sendo uma das camadas de células ectodérmicas, revestidas por células mesodérmicas, na área vitelina, de frente para o albúmen. No décimo primeiro dia de estudo, após um teste de imunocoloração, os autores observaram que a superfície interna do cório estava sendo completamente coberta pela membrana alantoica.

Baldavira (2017) mencionou que a membrana corioalantóide é altamente vascularizada e crucial para o desenvolvimento do embrião, pois faz o transporte de cálcio, a partir da casca do ovo e possui diversas funcionalidades tais como transporte de cálcio, troca gasosa, equilíbrio ácido-base e reabsorção de eletrólitos a partir da cavidade alantoica, onde se encontram os resíduos urinários, ressaltando sua importância para as aves.

\subsection{Utilização dos Anexos Embrionários em Pesquisas}

De acordo com o discorrido por Woodruff et al. (1931) a membrana corioalantóide estava sendo utilizada, em aves, por vários pesquisadores, para o estudo do crescimento de tecidos implantados. Narbaitz (1995) comentou que o interesse da pesquisa sobre a membrana corioalantóide, começou principalmente, devido à necessidade de relacionar as diferentes funções e identificar os componentes moleculares e mecanismos dessa membrana.

Com a membrana corioalantóide foram realizados ensaios para a avaliação toxicológica de produtos com baixo potencial de irritação ocular (Oliveira et al., 2012). 
Como também, a membrana corioalantóide de ovos de galinha já foi utilizada também para avaliação de efeitos toxicológicos de complexos de rutênio e para avaliar a viabilidade celular das linhagens de células LLC-MK2 (células de túbulo proximal renal de macaca mulata) por meio de teste de viabilidade celular (Lima, 2019).

Em relação ao saco vitelínico esse possui um nicho hematopoiético e por isso tem sido usado como modelo para entendimento dos eventos hematopoiéticos em mamíferos (Guedes et al., 2014). De acordo com Riveiros et al. (2010) o saco vitelínico pode ser utilizado para pesquisas com células-tronco, estudos proteômicos e terapia utilizando células para o tratamento de doenças.

Já quanto ao âmnio, recentemente autores têm visto grande potencial clínico-cirúrgico, sendo utilizado principalmente para estimular a cicatrização de lesões epiteliais e oculares, cirurgias vaginais reconstrutivas, reparo de hérnias abdominais, fechamento de pericárdio e prevenção de aderência cirúrgicas (Klein et al., 2011). Células derivadas da membrana amniótica e do líquido amniótico, apresentam plasticidade e potencial de células-troncos pluripotentes (Lange-Consiglio et al., 2012), e estas funções podem ser atribuídas a origem do âmnio, que é proveniente do epiblasto, este por sua vez dará origem às camadas germinativas (Favaron et al., 2015).

De acordo com Cardoso et al. (2014) o âmnio é uma fonte promissora de células tronco mesenquimais (CTM's), e já foi realizado com alguns grupos de mamíferos e podem ser executadas pesquisas utilizando o dos ovos de aves. A figura 1 demonstra os anexos embrionários de aves, a disposição desses e o início do desenvolvimento embrionário.

Figura 1. Os anexos embrionários de aves, a disposição desses e o início do desenvolvimento embrionário.

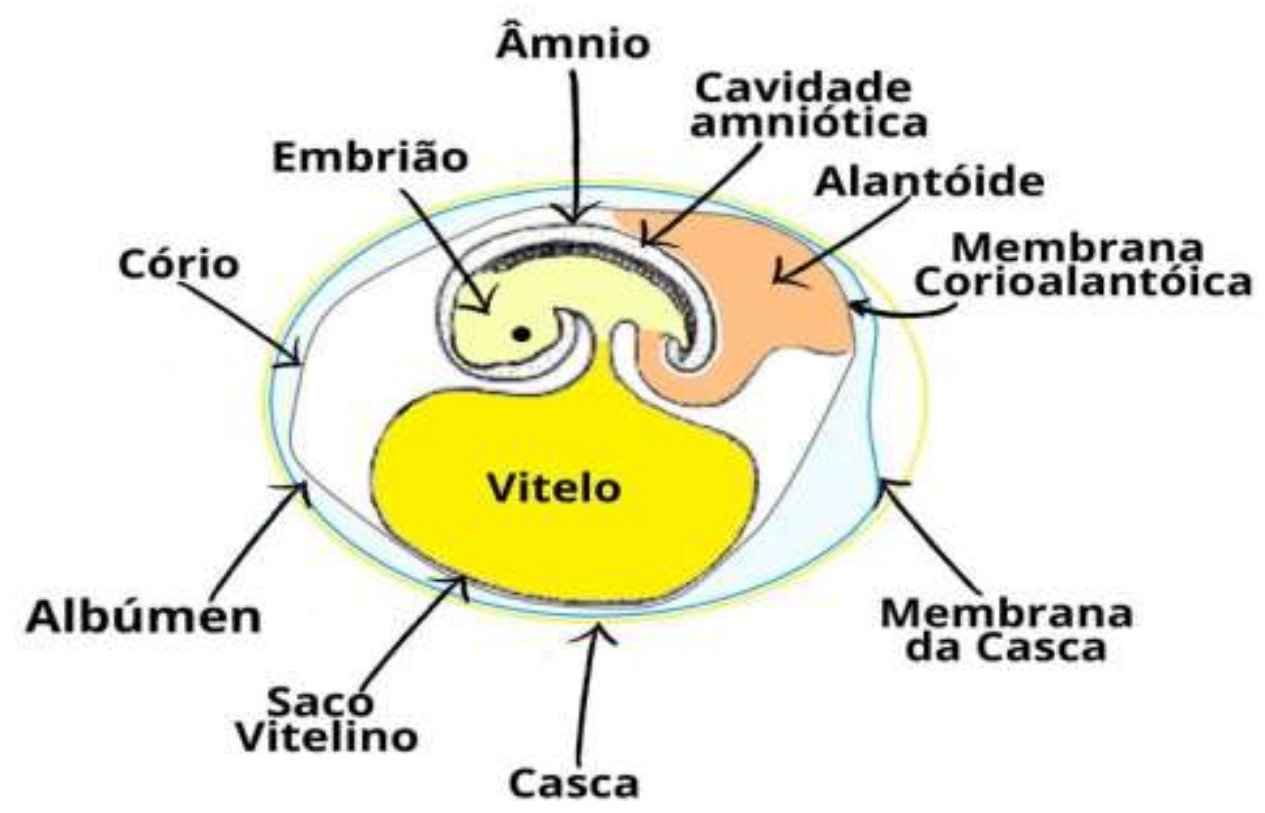

Fonte: Autores.

\section{Considerações Finais e Perspectivas Futuras}

Desta forma, o entendimento dos aspectos morfológicos dos anexos fetais forneceu informações que auxiliam na compreensão de vários mecanismos durante a formação do embrião e o progresso do desenvolvimento dentro do ovo. Visto que são estruturas importantes para o sucesso de uma boa formação e crescimento fetal, nutrição e proteção. 
Entretanto os estudos ainda são limitados e escassos, e necessitam de mais pesquisas que ajudem a compreender melhor compreensão seus aspectos embriológico, anatômico e fisiológico das espécies para que como consequência essa compreensão possa atribuir conhecimento para clínica de aves, e como modelos biológicos.

Assim, espera-se que este texto de revisão venha a contribuir com o melhor entendimento sobre o desenvolvimento e morfologia dos anexos embrionários das aves e que sirva de impulso para que novas pesquisas na área sejam desenvolvidas.

\section{Referências}

Ackerman, R.A., \& Rahn, H. (1980). In vivo O2 and water vapour permeability of the hen's. eggshell during early development. Respiration Physiology, 45(1), 1-8.

Baggott, G. K. (2009). Development of extra-embryonic membranes and fluid compartments. Avian Biology Research, 2(1-2), 21-26.

Bakst, M. R., \& Howarth Jr, B. (1977). The fine structure of the hen's ovum at ovulation. Biology of Reproduction, 17(3), 361-369.

Baldavira, C. M. (2017). Estudo do efeito da beta 2-glicoproteína I no desenvolvimento da rede vascular de membrana corioalantóica de embriões de galinha [Doctoral dissertation, Universidade de São Paulo].

Bellairs, R., \& Osmond, M. (2005). Atlas of chick development. Elsevier.

Björkman, N. (1982). Placentação. In: Dellman H, Broun EM (Ed.). Histologia Veterinária. Guanabara Koogan. Guanabara Koogan, $279-294$.

Burton, F. G., \& Tullett, S. G. (1985). Respiration of avian embryos. Comparative Biochemistry and Physiology Part A: Physiology, 82(4), 735-744.

Cardoso, M. T., Vidane, A. S., Martins, D. D. S., \& Ambrósio, C. E. (2014). An useful source of stem cells: the cat and dog amnion. Acta Veterinaria Brasilica, 8(2), 269-274.

Carrer, C. C. (2000). O mercado de avestruz. Anuário 2000 da avicultura industrial. Gessulli Agribusiness, 90(1074),68-74.

Chang, Y. J., Hwang, S. M., Tseng, C. P., Cheng, F. C., Huang, S. H., Hsu, L. F., Hsu, L.W., \& Tsai, M. S. (2010). Isolation of mesenchymal stem cells with neurogenic potential from the mesoderm of the amniotic membrane. Cells Tissues Organs, 192(2), 93-105.

Conrado, A. D. C., Lopes, S. T. D. A., Martins, D. B., Duarte, M. F., Mortari, A. C., Flores, M. L., \& Barasuól, L. (2007). Eletroforese das proteínas plasmáticas em emas (Rhea americana) de diferentes faixas etárias. Ciência Rural, 37(4), 1033-1038.

Deeming, C. (2002). Avian Incubation: Behaviour, Environment and Evolution. Oxford University Press.119, 1210-1211.

Dertkigil, M. S. J., Cecatti, J. G., Cavalcante, S. R., Baciuk, É. P., \& Bernardo, A. L. A. (2005). Líquido amniótico, atividade física e imersão em água na gestação. Revista Brasileira de Saúde Materno Infantil, 5(4), 403-410.

Dieterlen-Lièvre, F., Corbel, C., \& Salaün, J. (2010). Allantois and placenta as developmental sources of hematopoietic stem cells. International Journal of Developmental Biology, 54(6-7), 1079-1087.

Fairchild, B. D., Northcutt, J. K., Mauldin, J. M., Buhr, R. J., Richardson, L. J., \& Cox, N. A. (2006). Influence of water provision to chicks before placement and effects on performance and incidence of unabsorbed yolk sacs. Journal of applied poultry research, 15(4), 538-543.

Favaron, P. O., Carvalho, R. C., Borghesi, J., Anunciação, A. R. A., \& Miglino, M. A. (2019). Potential application of aminiotic stem cells in veterinary medicine. Animal Reproduction, 16(1), 24.

Ferner, K., \& Mess, A. (2011). Evolution and development of fetal membranes and placentation in amniote vertebrates. Respiratory physiology \& neurobiology, 178(1), 39-50.

Flumerfelt, B. A., \& Gibson, M. A. (1969). The histology and histochemistry of the developing chorioallantoic membrane in the chick (Gallus domesticus). Canadian Journal of Zoology, 47(3), 323-331.

Gabrielli, M. G., \& Accili, D. (2010). The chick chorioallantoic membrane: a model of molecular, structural, and functional adaptation to transepithelial ion transport and barrier function during embryonic development. Journal of Biomedicine and Biotechnology.

Galdos-Riveros, A. C., Rezende, L. C., Turatti, A. G., \& Miglino, P. M. A. (2010). A relação biológica entre o saco vitelino e o embrião. Enciclop Biosfera, 6, $1-13$.

Garcia, S. M. L., \& Fernandez, C. (2006). Embriologia. (2a ed.), Artmed.

Gipson, I. (1974). Electron microscopy of early cleavage furrows in the chick blastodisc. Journal of ultrastructure research, $49(3), 331-347$.

Godbert, R. S., \& Guyot, N. (2018). Vitellogenesis and Yolk Proteins, Birds. National Institute of Agronomic Research, 06, $278-284$.

Gucciardo, L., Lories, R., Ochsenbein-Kölble, N., Zwijsen, A., \& Deprest, J. (2009). Fetal mesenchymal stem cells: isolation, properties and potential use in perinatology and regenerative medicine. BJOG: An International Journal of Obstetrics \& Gynaecology, 116(2), 166-172. 
Guedes, P. T., de Abreu Manso, P. P., Caputo, L. F. G., Cotta-Pereira, G., \& Pelajo-Machado, M. (2014). Histological analyses demonstrate the temporary contribution of yolk sac, liver, and bone marrow to hematopoiesis during chicken development. PloS one, 9(3), e90975.

Hincke, M. T., Da Silva, M., Guyot, N., Gautron, J., McKee, M. D., Guabiraba-Brito, R., \& Réhault-Godbert, S. (2019). Dynamics of structural barriers and innate immune components during incubation of the avian egg: critical interplay between autonomous embryonic development and maternal anticipation. Journal of innate immunity, 11(2), 111-124.

Kochav, S., Ginsburg, M., \& Eyal-Giladi, H. (1980). From cleavage to primitive streak formation: a complementary normal table and a new look at the first stages of the development of the chick: II. Microscopic anatomy and cell population dynamics. Developmental biology, 79(2), 296-308.

Lange-consiglio, A., Corradetti, B., Bizzaro, D., Magatti, M., Ressel, L., Tassan, S., Parolini, O., \& Cremonesi, F. (2012). Characterization and potential applications of progenitor-like cells isolated from horse amniotic membrane. Journal of Tissue Engineering and Regenerative Medicine, 6(8), 622-635.

Lima, N.C.B. Utilização do ensaio da membrana cório-alantoide (HET-CAM) para análise do efeito irritante de complexos de rutênio. [Trabalho de conclusão de curso]. Fortaleza: UECE, 2019.

Lusimbo, W. S., Leighton, F. A., \& Wobeser, G. A. (2000). Histology and ultrastructure of the chorioallantoic membrane of the mallard duck (Anas platyrhynchos). The Anatomical Record: An Official Publication of the American Association of Anatomists, 259(1), 25-34.

Mess, A. (2003). Evolutionary transformations of chorioallantoic placental characters in Rodentia with special reference to hystricognath species. Journal of Experimental Zoology Part A: Comparative Experimental Biology, 299(1), 78-98.

Metcalfe, J., Stock, M. K., \& Ingermann, R. L. (1987). Development of the Avian Embryo: International Union of Physiological Sciences Satellite Symposium, Lester B. Pearson College of the Pacific, Victoria, British Columbia, Canada, 19-22, 1986. AR Liss.

Monteiro, A. P. (2017). Histologia e Embriologia Comparada. $1^{\circ}$ edição. Londrina: Editora e Distribuidora Educacional S.A.

Mortola, J. P. (2009). Gas exchange in avian embryos and hatchlings. Comparative Biochemistry and Physiology Part A: Molecular \& Integrative Physiology, 153(4), 359-377.

Mossman, H. W. (1987). Vertebrate fetal membranes: Comparative ontogeny and morphology. Evolution, Phylogenetic Significance, Basic Functions, Research Opportunities (New Brunswick, NJ, Rutgers University Press), London.

Narbaitz, R., Bastani, B., Galvin, N. J., Kapal, V. K., \& Levine, D. Z. (1995). Ultrastructural and immunocytochemical evidence for the presence of polarised plasma membrane $\mathrm{H}(+)$-ATPase in two specialised cell types in the chick embryo chorioallantoic membrane. Journal of Anatomy, 186 (Pt 2 ), 245.

Oliveira, A. G. L. D., Silva, R. S., Alves, E. N., Presgrave, R. D. F., Presgrave, O. A. F., \& Delgado, I. F. (2012). Ensaios da membrana cório-alantoide (HETCAM e CAM-TBS): alternativas para a avaliação toxicológica de produtos com baixo potencial de irritação ocular.

Padgett, C. S., \& Ivey, W. D. (1960). The normal embryology of the Coturnix quail. The Anatomical Record, 137(1), 1-11.

Piechotta, R., Milakofsky, L., Nibbio, B., Hare, T., \& Epple, A. (1998). Impact of exogenous amino acids on endogenous amino compounds in the fluid compartments of the chicken embryo. Comparative Biochemistry and Physiology Part A: Molecular \& Integrative Physiology, 120(2), 325-337.

Pereira, A. S., Shitsuka, D. M., Parreira, F. J., \& Shitsuka, R. (2018). Metodologia da Pesquisa Científica. UFSM.

Randles Jr, C. A., \& Romanoff, A. L. (1954). The buffering capacities of allantoic and amniotic fluids of the chick. Archives of Biochemistry and Biophysics, 49(1), 160-167.

Ribatti, D. (2012). Chicken chorioallantoic membrane angiogenesis model. In Cardiovascular Development (pp. 47-57). Humana Press.

Romanoff, A. L. The Avian Embryo. Macmillan (1960).

Schrode, N., Xenopoulos, P., Piliszek, A., Frankenberg, S., Plusa, B., \& Hadjantonakis, A. K. (2013). Anatomy of a blastocyst: cell behaviors driving cell fate choice and morphogenesis in the early mouse embryo. Genesis, 51(4), 219-233.

Shbailat, S. J., \& Abuassaf, R. A. (2018). Transfer of egg white proteins and activation of proteases during the development of Anas platyrhynchos domestica embryo. Acta Biologica Hungarica, 69(1), 72-85.

Sheng, G. (2014). Day 1 chick development. Developmental Dynamics. 243(3), 357-367.

Sheng, G., \& Foley, A. C. (2012). Diversification and conservation of the extraembryonic tissues in mediating nutrient uptake during amniote development. Annals of the New York Academy of Sciences, 1271(1), 97

Silva, M., Labas, V., Nys, Y., \& Réhault-Godbert, S. (2017). Investigating proteins and proteases composing amniotic and allantoic fluids during chicken embryonic development. Poultry Science, 96(8), 2931-2941.

Starck, J. M. (2020). Morphology of the avian yolk sac. Journal of Morphology.

Stern, C. D. (2004). The chick embryo--past, present and future as a model system in developmental biology. Mechanisms of Development, 121(9), 1011-1013.

Vanderley, S. B. S. C., \& Santana, H. C. I. (2015). Histologia e Embriologia Animal Comparada. (2a ed.). Editora da Universidade Estadual do Ceará Editora UECE.

Vargas, A., Zeisser-Labouèbe, M., Lange, N., Gurny, R., \& Delie, F. (2007). The chick embryo and its chorioallantoic membrane (CAM) for the in vivo evaluation of drug delivery systems. Advanced Drug Delivery Reviews, 59(11), 1162-1176. 
Research, Society and Development, v. 10, n. 2, e54310212498, 2021

(CC BY 4.0) | ISSN 2525-3409 | DOI: http://dx.doi.org/10.33448/rsd-v10i2.12498

Winter, V., Elliott, J. E., Letcher, R. J., \& Williams, T. D. (2013). Validation of an egg-injection method for embryotoxicity studies in a small, model songbird, the zebra finch (Taeniopygia guttata). Chemosphere, 90(1), 125-131.

Wong, F., Welten, M. C., Anderson, C., Bain, A. A., Liu, J., Wicks, M. N., Pavlovska, G., Davey, M. G., Murphy, P., Davidson, D., Tickle, C. A., Stern, C. D., Baldock, R. A., \& Burt, D. W. (2013). eChickAtlas: an introduction to the database. Genesis, 51(5), 365-371.

Wooding, F. B. P., \& Flint, A. P. F. (1994). Placentation In: Lamming GH (ed.), Marshall's Physiology of Reproduction.

Woodruff, A. M., \& Goodpasture, E. W. (1931). The susceptibility of the chorio-allantoic membrane of chick embryos to infection with the fowl-pox virus. The American Journal of Pathology, 7(3), 209.

Yadgary, L., Yair, R., \& Uni, Z. (2011). The chick embryo yolk sac membrane expresses nutrient transporter and digestive enzyme genes. Poultry Science, 90(2), 410-416

Yoshizaki, N., Soga, M., Ito, Y., Mao, K. M., Sultana, F., \& Yonezawa, S. (2004). Two-step consumption of yolk granules during the development of quail embryos. Development, Growth \& Differentiation, 46(3), 229-238.

Yuan, Y. J., Xu, K., Wu, W., Luo, Q., \& Yu, J. L. (2014). Application of the chick embryo chorioallantoic membrane in neurosurgery disease. International Journal of Medical Sciences, 11(12), 1275. 